\title{
"OS MENINOS DIANTE DE NÓS": EDUCAÇÃO, ARTE E POLÍTICA NA EXPOSIÇÃO DE DESENHOS DE ESCOLARES BRITÂNICOS (1941) ${ }^{1}$
}

\author{
Dulce Regina Baggio Osinski²
}

\section{RESUMO}

Este artigo analisa a Exposição de Desenhos de Escolares Britânicos, ocorrida no Museu Nacional de Belas Artes (MNBA) do Rio de Janeiro em 1941, como um esforço de propaganda da cultura britânica nas Américas tendo em conta o contexto da Segunda Guerra Mundial, mas também como parte de um conjunto de iniciativas educacionais envolvendo arte, voltadas para o público infantil e desenvolvidas ao longo da primeira metade do século XX. Para pensar a arte infantil em perspectiva moderna, se faz relevante o diálogo com as reflexões de Touraine e Berman, numa abordagem que privilegia uma lente mais aproximada em relação ao evento histórico, conforme os jogos de escala referidos por Lepetit, Gribaudi e Revel. Como fontes, foram utilizados artigos de jornais e catálogos de exposições.

Palavras-chave: exposição de arte infantil, história da educação em arte, criança e guerra.

\footnotetext{
${ }^{1}$ Uma versão preliminar deste texto, intitulada "Guerra e arte na Exposição de Desenhos de Escolares Britânicos (1941)" foi apresentada no 24 Encontro Anual da ANPAP (Associação Nacional de Pesquisadores em Artes Plásticas), ocorrido em Santa Maria (RS), no período entre 22 e 26 de setembro de 2015.

2 Universidade Federal do Paraná (UFPR), Curitiba, Brasil.
} 


\section{"LOS NIÑOS DELANTE DE NOSOTROS": EDUCACIÓN, ARTE Y POLÍTICA EN LA EXPOSICIÓN DE DISEÑOS DE ESCOLARES BRITÁNICOS (1941)}

\section{RESUMEN}

Este artículo analiza la Exposición de Dibujos de Escolares Británicos, ocurrida en el Museo Nacional de Bellas Artes (MNBA) de Río de Janeiro en 1941, como un esfuerzo de propaganda de la cultura británica en las Américas teniendo en cuenta el contexto de la Segunda Guerra Mundial, pero también como parte de un conjunto de iniciativas educativas que implicaban el arte, dirigidas al publico infantil y desarrolladas a lo largo de la primera mitad del siglo XX. Para pensar el arte infantil en perspectiva moderna se hace relevante el diálogo com las reflexiones de Touraine y Berman, en un enfoque que privilegia una lente más aproximada em relación al acontecimiento histórico, conforme a los juegos de escala referidos por Lepetit, Gribaudi y Revel. Como fuentes, se utilizaron artículos de periódicos y catálogos de exposiciones.

Palabras clave: exposición de arte infantil, historia de la educación en arte, el niño y la guerra.

\section{"THE CHILDREN IN FRONT OF US": EDUCATION, ART AND POLITICS AT THE BRITISH SCHOOLCHILDREN'S DRAWINGS EXHIBITION (1941)}

\section{ABSTRACT}

This article analyzes the British Children's Drawings Exhibition, held at the National Museum of Fine Arts (MNBA) in Rio de Janeiro in 1941, as an effort to publicize British culture in the Americas in the context of World War II, but also as part of a series of educational initiatives involving art aimed at children and developed during the first half of the twentieth century. In order to think about children's art in a modern perspective, the dialogue with Touraine and Berman's reflections becomes relevant in an approach that privileges a closer lens in relation to the historical event, according to the scale games referred to by Lepetit, Gribaudi and Revel. As sources, we used newspaper articles and exhibition catalogs.

key-words :Child art exhibition, history of art education, child and war.

\section{"LES ENFANTS DEVANT NOUS": ÉDUCATION, ART ET POLITIQUE DANS L'EXPOSITION DE DESSINS DES ÉLEVES BRITANNIQUES (1941)}

\section{RÉSUMÉ}

Cet article analyse l'Exposition de Dessins d'Ècoliers Britanniques organisée au Musée National des Beaux-arts de Rio de Janeiro en 1941, dans le but de faire connaître la culture britannique dans les Amériques à la lumière du contexte de la Seconde Guerre mondiale, mais aussi dans le cadre d'un ensemble d'initiatives éducatives impliquant l'art, destinées aux enfants et développées au cours de la première moitié du vingtième siècle. Afin de reflechir à l'art des enfants dans une perspective moderne, le dialogue avec Touraine et Berman devient pertinent 
dans une approche qui privilégie une perspective plus proche de l'événement historique, selon les jeux d'échelle mentionnés par Lepetit, Gribaudi et Revel. Des articles de journaux et des catalogues d'expositions ont été utilisés comme sources.

Mots-clés: exposition d'art enfantin, histoire de l'éducation artistique, enfant et guerre. 


\section{INTRODUÇÃO}

A ideia de modernidade, concebida como a afirmação da racionalidade instrumental expressa pela ciência, pela tecnologia e pela administração, também contém em seu bojo, como observa Touraine (1994), a valorização da subjetividade e o desejo de libertação de toda forma de opressão. No contexto europeu pós-revolução francesa permeado por ideias iluministas, toma corpo, como um dos desdobramentos modernos, a noção da infância como etapa relevante e separada da vida adulta. Rousseau já era partidário, em pleno século XVIII, de uma educação que respeitasse as necessidades específicas da criança, tendo sido um dos primeiros a reconhecer a importância de sua manifestação livre por meio da arte.

A partir de meados do século XIX até a primeira metade do século XX, esse pensamento se intensificou quando teóricos e educadores ${ }^{3}$ passaram a defender a prática artística infantil como parte dos processos de desenvolvimento humano. Com o advento das vanguardas artísticas europeias, algumas características comuns entre os trabalhos de crianças e de artistas representativos de correntes como o fauvismo 4 ou o expressionismo 5 passaram

\footnotetext{
3 Entre os muitos intelectuais que incluíram questões referentes à produção artística infantil em suas reflexões podemos citar Pestalozzi, Froebel, Spencer e Sully, no século XIX, e Dewey, Cizek, Richardson, Read e Lowenfeld, no século XX (Kelly, 2004).

4 A denominação de "fauves" (feras, em francês) foi atribuída pelo crítico Louis Vauxcelles a um grupo de artistas integrado por Henri Matisse, Andre Derain, Maurice Vlamink, Albert Marquet e Georges Rouault por ocasião do Salão de Outono de 1905, ocorrido em Paris, cujos trabalhos se encontravam na mesma sala em que Henri Rousseau expunha uma pintura intitulada "O Leão Faminto". Fazendo uma analogia provavelmente depreciativa com a temática explorada por Rousseua, Vauxcelles se referia às características estilísticas das pinturas expostas por seus companheiros de sala, cuja liberdade de expressão se traduzia no uso de cores puras e fortes, desvinculadas de referenciais externos, no exagero do desenho e na deformação da perspectiva. (WHITFIELD, 1991; SELZ, 1996).

5 Termo relacionado a dois grupos informais de artistas alemães: o Die Brücke (A Ponte), de Desdren, formado em 1905 e dissolvido em 1913, e que congregava artistas como Emil Nolde, Ernst Ludwig Kirchner, Karl Schmidt-Rottluff e Herich Heckel; e o dos artistas de Munique que se reuniam em torno de uma revista intitulada Der Blaue Reiter (O Cavaleiro Azul), que teve seu único número publicado em 1912, entre os quais podem ser citados Wassily Kandinsky, Paul Klee e Franz Marc. Com características semelhantes às dos fauvistas no que se refere aos aspectos formais, apostavam num subjetivismo antinaturalista, explorando contrastes marcantes e buscando atingir um público mais vasto por meio de linguagens como a xilogravura ou a litografia, além da pintura (LYNTON, 1991, SELZ, 1996).
} 
a ser valorizadas, a exemplo do uso de cores puras e intensas, de pinceladas livres ou da deformação, ou mesmo da metodologia de trabalho, que pretensamente privilegiava a intuição em detrimento de convenções estabelecidas ou conhecimentos pré-adquiridos. O termo "arte infantil", adotado a partir das primeiras décadas do século $\mathrm{XX}$, tinha como pressupostos, de acordo com Viola (1936, p. 9), a compreensão de que essa é uma manifestação inerente à criança, expressando sua personalidade a partir de uma lógica própria; e a convicção de que tal expressão, sendo criativa e única, nunca poderia ser relacionada a ideias como talento, exatidão ou cópia da natureza. Nesse contexto, a publicização da produção imagética infantil por meio de exposições tornou-se frequente, sendo pensada como estratégia de defesa da liberdade de expressão da criança e de uma educação baseada nesse princípio.

Sobre as ações relacionando educação em arte no Brasil, voltadas ao público infantil, a historiografia aponta para experiências realizadas por artistas e intelectuais modernos como Anita Malfatti e Mário de Andrade que, já nos anos de 1920, desenvolveram projetos educacionais voltados para a expressão artística da criança ${ }^{6}$. A valorização do papel da arte também marcou presença na cena educacional vinculada ao movimento pela Escola Nova, especialmente nas reformas empreendidas a partir do diálogo com as ideias de John Dewey. Isso é perceptível na reforma da instrução pública do Distrito Federal (19271929), implementada entre 1927 e 1929 por Anísio Teixeira, mas também na reforma Francisco Campos, de Minas Gerais em 1928, que contou com a colaboração da educadora e artista suíça Artus Perrelet, e na empreendida por Carneiro Leão em 1928 em Pernambuco (BARBOSA, 2001).

A exposição de crianças inglesas, organizada no Rio de Janeiro em 1941 pelo Conselho Britânico, é considerada um marco na cena cultural e educacional brasileira e fator motivador para projetos posteriormente empreendidos em outras regiões do Brasil, as quais incluíam, além de eventos congêneres,

\footnotetext{
${ }^{6}$ Ver, entre outros, Barbosa (1978), Osinski (2006) e Gobbi (2006).
} 
também ações educacionais que ficaram conhecidas como "escolinhas de arte" Por esse motivo, torna-se relevante tomá-la como objeto de estudo ${ }^{8}$, buscando uma aproximação no jogo de escalas possível no processo de análise histórica de acordo com as reflexões de Revel (1998), a qual torna visíveis aspectos que passam despercebidos por ocasião de análises de caráter temporal ou temático mais abrangente. Segundo o autor,

[...] a escolha de uma escala particular de observação produz efeitos de conhecimento, e pode ser posta a serviço de estratégias de conhecimentos. Variar a objetiva não significa apenas aumentar (ou diminuir) o tamanho do objeto no visor, significa modificar sua forma e sua trama. (REVEL,1998, p. 20).

Assumindo um recorte temporal relativamente restrito e focando num acontecimento específico, no caso um projeto de exposição de arte infantil, tentaremos pensá-lo como parte de um movimento mais amplo, no sentido de compreender suas justificativas estéticas e educacionais, o impacto que provocou junto à comunidade que a acolheu, o entusiasmo com o qual foi recebido pela comunidade intelectual e artística e suas implicações de ordem política. De acordo com Gribaudi (1998, p. 132), tal enfoque, de natureza microanalítica, "individualiza os conteúdos para além nível formal dos fenômenos", sendo que "a significação dos comportamentos, assim como das representações, é encontrada nas intenções dos atores, captadas em seus contextos".

Buscamos, assim, "privilegiar a experiência dos atores reconstruindo em torno dela o contexto [...] que lhe dá sentido e forma” (REVEL, 1998, p. 13). Concordamos com Lepetit (1998, p. 100) quando afirma que "a escolha de uma

\footnotetext{
7 O termo "escolinha de arte", criado nos anos 1940 pelo artista e educador Augusto Rodrigues, criador da Escolinha de Arte do Brasil (INEP, 1980, p. 39) é utilizado, no contexto brasileiro, para denominar espaços extracurriculares dedicados à atividade artística com crianças dentro de uma metodologia que privilegia a expressão livre da criança, com o mínimo de interferência do educador.

8 Sobre exposições de arte infantil, ver Barbosa (2013); Osinski (2014); Osinski, Antonio (2010a e 2010b) e Osinski, Simão (2014); e Osinski, Silva (2015).
} 
escala particular tem como efeito modificar a conformação e a organização dos objetos”, não constituindo, entretanto, um privilégio especial, mas uma forma de abordagem que pode ser considerada complementar a movimentos de análise mais abrangente. As diferentes possibilidades de escalas analíticas seriam, nesse sentido, "modalidades diferentes da formalização causal dos fenômenos sociais e das evoluções históricas” (GRIBAUDI, 1998, p. 121).

Os jornais diários e os periódicos em circulação no período9, tomados como fontes privilegiadas desta pesquisa, possibilitam um olhar para além do acontecimento em si, no qual objeto e contexto se encontram enredados. Produtos essencialmente urbanos, suas páginas nos permitem sentir o pulsar das cidades, dando uma ampla visada "dos personagens ilustres aos anônimos, do plano público ao privado, do político ao econômico, do cotidiano ao evento, da segurança pública às esferas cultural e educacional" (VIEIRA, 2007, p. 13). Também por meio delas temos acesso às manifestas opiniões de intelectuais e artistas as quais trazem à cena aspectos das ideias circulantes sobre arte e educação, sobre o papel da produção infantil nesse contexto e sobre seu uso político. Outros documentos, como os catálogos das exposições, subsidiam esta análise, trazendo informações objetivas sobre a organização do evento, além de textos institucionais assinados pelos organizadores.

\section{UMA MOSTRA DE ARTE INFANTIL: ENTRE FINS EDUCACIONAIS E PROPAGANDA POLÍTICA}

Em meados de setembro de 1941, em meio a notícias da guerra travada na Europa, como os bombardeios a Londres pelas forças hitleristas, os jornais

\footnotetext{
9 A busca aos artigos foi realizada na Hemeroteca Digital da Biblioteca Nacional, nos jornais disponibilizados naquela plataforma, delimitando-se o período da década de 1940, mediante o uso de palavras-chave correlatas ao assunto, entre as quais descatamos: "exposição de desenhos de crianças", "exposição infantil", "arte infantil", "exposição de crianças inglesas" e "Museu Nacional de Belas Artes". Entre os jornais consultados, elencamos: A Manhã , Correio da Manhã, Diário Carioca, Diário da Noite, Diário de Notícias, Gazeta de Notícias e O Jornal (Rio de Janeiro); Correio Paulistano e O Estado de São Paulo (São Paulo); Gazeta do Povo (Curitiba); e Diário de Pernambuco (Recife).
} 
que circulavam no Rio de Janeiro anunciaram, em pequenas notas, a realização próxima da "Exposição de Desenhos de Escolares Britânicos", a ser inaugurada em 11 de outubro daquele ano, nas dependências do Museu Nacional de Belas Artes. Organizada pelo Conselho Britânico, a mostra foi realizada sob os auspícios do Ministério de Educação e patrocinada pelo Instituto Nacional de Estudos Pedagógicos, pela Associação Brasileira de Educação, pela Associação dos Artistas Brasileiros e pela Sociedade Brasileira de Cultura Inglesa. (O JORNAL, 11 out. 1941, p. 10).

A iniciativa fazia parte de um conjunto de ações promovidas pela GrãBretanha, que visavam conquistar, no exterior, simpatizantes na luta contra o poderio militar alemão. Fundado em 1934 a partir de motivações consideradas ameaçadoras como a tomada do poder na Rússia pelos bolcheviques em 1917, a ascensão de Mussolini em 1922 e a tomada de poder por Hitler em 1933, o Conselho Britânico tinha como objetivo o fortalecimento de sua influência na Europa e em outros continentes. Seus propósitos foram expressos no Relatório anual, de 1940-1941:

O objetivo do Conselho é criar num país de além-mar uma base de conhecimento amigável e entendimento de seu povo, de sua filosofia e modo de vida, que leve à apreciação simpática da política externa britânica, seja qual for o momento em que esta política se encontre e independente de suas convicções políticas. Se em tempos de perigo esse conhecimento amigável e entendimento se torna vital para que a guerra tenha uma solução de sucesso (esse é o lugar do Conselho no esforço de guerra), em tempos de paz sua importância não é menorio. (BRITISH COUNCIL, 2015)

O desejo de estreitamento das relações com os países americanos foi

\footnotetext{
${ }^{10}$ Tradução da autora. Do original: "The Council's aim is to create in a country overseas a basis of friendly knowledge and understanding of the people of this country, of their philosophy and way of life, which will lead to a sympathetic appreciation of British foreign policy, whatever for the moment that policy may be and from whatever political conviction it may spring. While in times of danger this friendly knowledge and understanding becomes vital to the successful prosecution of war (that is the Council's place in the war effort), in times of peace it is not less valuable". (BRITISH COUNCIL, 2015).
} 
expresso em irradiação feita em agosto de 1941 por Malcolm Robertson, então presidente do Conselho Britânico para a América Latina, na qual um apelo era feito para o estabelecimento de instituições sul-americanas na Inglaterra e em outras partes do mundo. Afirmando paradoxalmente não ter a Instituição objetivos políticos e não querer impor a outrem o ponto de vista particular ou o modo de viver britânico, enfatizava que para apreciar um povo, era necessário "estar um tanto ao corrente do seu idioma, literatura, artes, política e vida social" (DIÁRIO CARIOCA, 11 jul. 1941, p. 2). No âmbito do território brasileiro, a Sociedade Brasileira de Cultura Inglesa (SBCI), atuando desde 1934, cumpria os propósitos de difusão da cultura e da língua inglesas, atuando como parceira de instituições brasileiras em projetos de divulgação artística.

Thistlewood (1994, p. 375) especula sobre os motivos da opção por uma exposição infantil para representar artisticamente a Inglaterra em solo americano: "Como era considerado muito arriscado transportar pelo Atlântico trabalhos de estabelecida importância para a herança nacional, foi proposto que em seu lugar fossem enviados desenhos de crianças”. Essa hipótese é reforçada por outra atividade cultural ocorrida um pouco mais tarde, em 1942, a Exposição de Gravuras Britânicas Contemporâneas, também organizada pela SBCI e apresentada no Museu Nacional de Belas Artes do Rio de Janeiro. (CORREIO DA MANHÃ, 16 mai. 1942, p. 3). Assim como os trabalhos das crianças não detinham o mesmo valor simbólico ou de mercado que obras de arte únicas e consagradas, também as gravuras contemporâneas tinham seus riscos minimizados por se tratarem de obras múltiplas. No entanto, os resultados da exposição de escolares britânicos foram bastante satisfatórios, pois um relatório posterior ao projeto continha afirmações de que ela havia sido "a melhor propaganda que poderia haver" (BRITISH COUNCIL apud BARBOSA, 2015, p. 318).

Os 200 desenhos e pinturas da mostra, realizados por crianças e adolescentes de 3 a 17 anos, eram frutos das ações educacionais em arte desenvolvidas pelas escolas inglesas, públicas e particulares, primárias e 
secundárias, além de escolas de arte em menor número. A seleção foi feita por uma comissão especializada composta por professores e críticos de arte britânicos, entre eles Nommie Durell, da Nova Sociedade de Professores de Arte, Audrey Martin, ex-presidente da Sociedade de Professores de Arte, Herbert Read, escritor e crítico de arte, Mary Dudley Short, presidente da Sociedade e Professores de Arte, R. R. Tomlinson, do Conselho Municipal de Londres, Barclay-Russel, da Nova Sociedade de Professores de Arte, e major A. A. Longden, do Conselho Britânico (CORREIO DA MANHÃ, 12 out. 1941, p. 2).

O relatório feito pela comissão para o Conselho Britânico reafirma os objetivos políticos do projeto e das negociações feitas com países como os Estados Unidos, o Canadá e o Brasil para sua consecução. Também fala do processo de seleção dos trabalhos, que teria incluído a contribuição de entidades como a Society of Art Teachers e a Art Teachers Guild, que indicariam as instituições com melhor produção. Estavam previstas visitas a algumas escolas, feitas por Herbert Read e pelo Major Longden para escolher os trabalhos a serem enviados ao Conselho Britânico, para que fossem posteriormente selecionados pelo comitê. Foi sugerido, no referido documento, que a mostra fosse apresentada primeiramente na Grã-Bretanha, no British Institute of Adult Education, em Londres, seguindo posteriormente para as Américas do Norte e do Sul. No entanto, o presidente do comitê argumentou, à época, que a exposição poderia perder o interesse da imprensa no exterior se fosse mostrada antes na Inglaterra (BARBOSA, 2015, p. 317-318). Todavia, é possível que a mostra afinal tenha ocorrido primeiramente em território britânico, conforme planejado, tendo em vista o fato ter sido mencionado em matéria de um jornal brasileiro (DIÁRIO DE NOTÍCIAS, 11 out. 1941, p. 5).

Embora inicialmente tenha sido sugerido que fossem preparadas duas exposições, uma para o Canadá e Estados Unidos e outra menor para a América do Sul, ao final elas foram organizadas com o mesmo número de trabalhos e ocorreram simultaneamente, iniciando-se em 1941 e se prolongando até 1942. Para a mostra itinerante na América do Norte foram enviados trabalhos de 48 
instituições educacionais britânicas. Já do evento ocorrido no Brasil participaram escolares de 58 instituições, tendo variado o número de trabalhos enviados por cada uma delas. A Escola Charterhouse, de Surrey, o Convento Sagrado Coração, de Londres e a Escola Longford Grove, de Essex, contaram com uma representação maior em relação às outras em ambos os certames. Foram contempladas, além da capital britânica Londres, também outras localidades, como Oxford, Kent, Surrey, Berkshire ou Cambridge.

Jacques Revel nos alerta para o fato de que cada ator é partícipe, esteja perto ou distante, dos mais variados processos históricos, inscrevendo-se em contextos de dimensões e níveis variados, que vão do mais local ao global. Segundo ele, a experiência de indivíduos, grupos ou de espaços determinados permite a percepção de modulações particulares de uma história mais ampla (REVEL, 1998). Envolvendo um grupo numeroso de profissionais especializados em sua organização e mobilizando intelectuais, educadores e artistas no que se refere à sua recepção, a exposição de desenhos de crianças inglesas seguia uma orientação pedagógica cujas origens remetiam ao final do século XIX, quando personalidades como Thomas Ablett e R. Catterson Smith se engajaram na defesa da expressão individual das crianças. Acreditando que o verdadeiro objetivo da arte infantil deveria ser "desenhar por divertimento", Ablett fundou em 1888 a Sociedade Real de Desenho, que em 1890 organizou sua primeira exposição de desenhos de crianças, enquanto os métodos de Smith encorajavam os alunos a desenhar de memória. (THISTLEWOOD, 1983, p. 173). Já nos anos 1920 e 1930, a educadora Marion Richardson ${ }^{11}$, que havia sido aluna de Smith, iniciou um movimento reformador no ensino da arte inglês, no sentido de proporcionar às crianças liberdade para expressar suas ideias e emoções por meio de cores e formas, e encorajar sua vívida imaginação. Tais empreendimentos eram alimentados por eventos como as exposições organizadas regularmente na Inglaterra entre 1920 e 1935 por Franz Cizek ${ }^{12}$,

\footnotetext{
${ }^{11}$ Marion Richardson (1892-1946) foi uma educadora britânica defensora da auto-expressão de seus alunos.

${ }^{12}$ Franz Cizek (1865-1946) foi um educador austríaco que atuou em Viena na virada do século
} 
educador austríaco defensor da livre-expressão infantil.

As ideias de Richardson impressionaram o crítico de arte Roger Fry, que já havia organizado uma exposição de desenhos de filhos de artistas e que passou a defender a causa da arte infantil, relacionando-a com a arte moderna e com as manifestações artísticas dos povos ditos à época primitivos. Aderindo à estratégia da organização de exposições para dar visibilidade às suas propostas, Richardson associou-se a Barclay-Russell na realização de uma grande mostra de arte infantil em 1938, no County Hall, em Londres. Interessado pelas manifestações artísticas e professor de arte, Barclay-Russel organizaria, no mesmo período, uma exposição de arte adolescente no Morley College, também em Londres, a qual marcou a formação da Sociedade de Educação em Arte (THISTLEWOOD, 1983, p. 172), contribuindo, também para que o projeto do Conselho Britânico se efetivasse.

\section{A PRESENÇA DAS CRIANÇAS INGLESAS NOS SALÕES DO MUSEU NACIONAL DE BELAS ARTES}

“Agora os meninos estão diante de nós. Eles não vieram num navio. Mas mandaram suas telas e seus desenhos" (SILVEIRA, 16 out. 1941, p. 7). Assim o jornalista e escritor Joel Silveira se referiu à mostra recém inaugurada, a qual foi saudada pela imprensa. Sua importância foi ressaltada por comentaristas, pintores e artistas em geral, intelectuais e educadores, por representar "não somente um catálogo das atividades pictóricas da infância britânica, mas, também uma demonstração positiva dos resultados do ensino da arte às crianças" (A MANHÃ, 16 set. 1941, p. 8). A solenidade de abertura contou com uma grande afluência de público, atraindo a atenção da elite intelectual carioca, como sugere Silveira:

XIX para o XX. Tornou-se célebre por seu curso de "Arte jovem", introduzido em Viena em 1897 como escola privada, e integrado à Escola de Artes e Ofícios em 1904, o qual tinha como lema "Nada ensinar, nada aprender! Deixar crescer as próprias raízes" (WILSON, 1990, p. 56). 
Uma grande multidão encheu o Museu de Belas Artes sábado último. Todos foram ver as maravilhas dos meninos ingleses. Professores, alunos, mocinhas, artistas, rapazes, escritores, oradores, repórteres, fotógrafos, compositores populares, meninos vestidos de marinheiro, autoridades, economistas e poetas, todos estavam lá. Todos iam e voltavam diante dos quadros. Iam novamente, voltavam, cheios de admiração. (SILVEIRA, 16 out. 1941, p. 7)

O interesse despertado por setores especializados dos campos da arte e da educação, bem como pela população em geral, reafirmava a atenção dirigida à criança nas esferas social, cultural e governamental brasileiras. A publicação do decreto 2024, de 17 de fevereiro de 1940, que criava o Departamento Nacional da Criança e a Conferência de Proteção à Criança, entre outras medidas, davam visibilidade à política de Getúlio Vargas relacionada à infância, incentivando, além de providências na saúde e na educação, ações como os concursos de robustez infantil, motivados por ideias higienistas (A MANHÃ, 10 ago. 1941, p. 1), ou festas de "arte infantil", como a organizada pelo Tijuca Tennis Club, no ano anterior (CORREIO DA MANHÃ, 17 jul. 1940, p. 9). Festividades de final de ano voltadas aos pequenos, como a organizada pelo Rotary Club, e que reuniu três mil crianças das comunidades pobres do Rio de Janeiro, tinham lugar em recintos freqüentados pela sociedade local, como o Teatro São Caetano (O JORNAL, 31 dez. 1941, p. 7). Também artigos como o intitulado "A criança e seus problemas" (MARIA ISABEL, 16 set. 1941, p. 8), que discutiam questões relacionadas à infância concernentes a aspectos educacionais, psicológicos e de saúde, se faziam presentes nos jornais do país, levando à população informações atualizadas.

Nesse contexto, a realização de mostras como a proposta pelo Conselho Britânico também não era exatamente uma novidade. Barbosa (2012) menciona, como exemplo, uma exposição de crianças japonesas que aconteceu no Rio de Janeiro em 1928, e que teria entusiasmado os visitantes, logrando igualmente grande alcance de mídia. Diferindo das mostras escolares, marcadas por trabalhos de artesanato e desenho geométrico os quais, segundo Cecília Meireles (2001, p. 51), eram muitas vezes realizados com a ajuda de 
familiares ou professores, as exposições de arte infantil propunham uma abordagem na qual a individualidade e a espontaneidade da criança, bem como sua autonomia na realização dos trabalhos, eram valorizadas em detrimento de receitas ou fórmulas.

As notícias que circulavam no período podem nos dar uma ideia da atmosfera em que se inseria a exposição das crianças inglesas, a exemplo de artigo de autoria de Eleanor Roosevelt (07 mar. 1941, p. 5), publicado no Diário de Notícias em março daquele ano, em que a então primeira dama dos Estados Unidos registra a impressão positiva que teve em visita realizada a uma instituição de Washington, onde se realizavam exposições de arte infantil e atividades artísticas. Manifestando suas preocupações com as dificuldades de sobrevivência de um projeto como aquele em contexto de guerra, a autora afirmava a necessidade de sua preservação "no interesse da verdadeira defesa do nosso país”.

Eventos artísticos voltados às crianças também tinham lugar em diferentes cidades brasileiras, sendo noticiados pela imprensa. Naquele mesmo ano de 1941, acontecera em São Paulo, no mês de agosto, o $1^{0}$ Salão de Arte Infantil (A MANHÃ, 10 out. 1941, p. 1), do qual participaram meninos e meninas da capital e do interior e de cuja comissão fizeram parte Amadeu Amaral Junior e o artista Flávio de Carvalho, entre outros (DIÁRIO DA NOITE, 01 ago. 1941, p. 5). De caráter competitivo, o certame contava com um júri especializado e conferia premiações aos melhores trabalhos.

Chama a atenção, porém, pela aparente semelhança com o projeto britânico, a exposição de desenhos de crianças francesas, organizada pela Escola Nacional de Belas Artes, e que teve lugar cerca de dois meses antes, em agosto de 1941 nas mesmas dependências do Museu Nacional de Belas Artes. Apresentando quinhentos desenhos, escolhidos entre os três milhões oferecidos ao Marechal Pétain, chefe de estado da França de Vichy, por ocasião do Natal anterior, a mostra contou, em sua inauguração, com a presença de autoridades como o embaixador da França e os diretores do Museu e da Escola Nacional de 
Belas Artes (CORREIO DA MANHÃ, 30 ago. 1941, p. 3). Entretanto, causou pouco impacto na mídia, merecendo apenas breves menções nos jornais locais, em sua maioria meramente informativas, o que pode ser explicado pela natureza colaboracionista daquele governo em relação ao nazismo.

Não obstante, em meio ao silenciamento da comunidade artística e intelectual, alguns comentários puderam ser encontrados de maneira esparsa, a exemplo de nota publicada no Diário de Notícias, que elogiava o talento precoce e a sensibilidade artística dos meninos franceses que dando "livre curso à sua imaginação [...] interpretaram, nesses desenhos, os mais variados assuntos" (DIÁRIO DE NOTÍCIAS, 28 ago. 1941, p. 11). Ignorando as implicações políticas e éticas de tal uso da infância, outras matérias recomendavam uma visita à mostra como um espetáculo que valia a pena ser visto, não só pela variedade dos desenhos apresentados, mas também por possibilitarem "conhecer de perto a vida francesa, os costumes, as paisagens, através da ingenuidade das crianças” (GAZETA DE NOTÍCIAS, 30 ago. 1941, p. 13).

São dignos de nota, também, os comentários publicados no Correio da Manhã, os quais se referem a uma "França cheia de convicção patriótica" e que "a cada momento aumenta suas energias", afirmando serem os trabalhos expostos uma "maravilhosa lição de civismo" e as crianças os "pequeninos heróis da França atual” (CORREIO DA MANHÃ, 30 ago. 1941, p. 3). Expressando uma das faces da suposta neutralidade do Governo de Vargas e também da sociedade brasileira diante do conflito mundial, nenhuma das matérias encontradas sobre essa exposição faz qualquer alusão aos avanços de Hitler ou à atitude daquela parte da França, que capitulou sem resistência diante das forças alemãs.

Contrastando com os temas dos trabalhos presenteados a Pétain, que segundo a imprensa da época evocavam situações do cotidiano permeadas de certa normalidade, a fome sofrida pelas crianças na França não ocupada era tema de notícias, como a publicada dias antes pela Gazeta de Notícias, sobre a proposta dos Estados Unidos, de angariar fundos para auxiliar 300 mil crianças 
francesas em situação de penúria. (GAZETA DE NOTÍCIAS, 24 ago. 1941, p. 22). Os depoimentos das crianças das escolas de Tournissan (CAZALS, 1978), pequena vila de apenas 400 habitantes e que à época se encontrava em território ocupado, também nos fazem refletir sobre as dificuldades por elas enfrentadas. Orientados por Jean Puget, educador comprometido com métodos pedagógicos baseados nas ideias de Freinet, esses meninos e meninas produziram, como atividades escolares, textos e imagens que constituem verdadeiro testemunho do período que inclui as mobilizações precedentes, a declaração de guerra, as condições de vida e a posição de não aceitação da invasão alemã. Em seus relatos, questões como o racionamento de alimentos e a falta de vestimentas aparecem em destaque. Ao mesmo tempo em que a população carioca apreciava as imagens coloridas no Museu, os pequenos franceses de Tournissan, cujos trabalhos só vieram a público posteriormente, relatavam as privações que levavam a população a recorrer a ratos, rãs e ouriços como parte de suas refeições. Desta forma, os propósitos das autoridades francesas de angariar simpatia dos brasileiros num contexto internacional conturbado e dividido, se não passaram despercebidos aos jornalistas brasileiros, também não foram por eles tensionados ou questionados.

Ao contrário do que ocorreu com a exposição de crianças francesas, a mostra organizada pelo Conselho Britânico logrou grande repercussão na imprensa, sendo evidenciadas tanto suas qualidades pedagógicas como também, de forma menos enfática, sua dimensão política. Isso foi notado já no texto de apresentação publicado no catálogo da mostra, de autoria de Herbert Read (1893-1968). Poeta, crítico literário, filósofo e historiador da arte vinculado ao movimento anarquista, Read já gozava naquele movimento de reconhecimento profissional nos campos da arte e da literatura ${ }^{13}$, tendo assumido a organização

\footnotetext{
${ }^{13}$ Herbert Read havia sido professor de belas artes na Universidade de Edinburgh no período entre 1931 e 1933, tendo sido um dos organizadores da Exposição Internacional de Surrealismo, ocorrida em 1936. Entre os trabalhos publicados até aquele momento estão: Reason and Romanticism (1926); The Meaning of Art (1931); The Anatomy of Art: An Introduction to the Problems of Art and Aesthetics (1932); Art Now: An introduction to the Theory of Modern Painting and Sculpture (1933); The Innocent Eye (1933); e Art and Industry:The Principles of Industrial Design (1934). (ENCICLOPAEDIA BRITANNICA, 2019;
} 
do certame em suas diversas fases.

Citando pioneiros reformadores como Franz Cizek, Ebenezer Cook e James Sully, Read (1941-1942a, p. 4) ressaltou o grau de importância que a arte vinha conquistando nos currículos escolares nos últimos quarenta anos, relacionando a valorização da arte infantil à apreciação crescente da pintura moderna e da arte primitiva. Para ele, o caráter universal das manifestações artísticas infantis podia ser percebido na semelhança entre os trabalhos de crianças de diferentes partes do planeta, resultado de sua espontaneidade e fruto mais da sensibilidade que do intelecto:

A criança exprime características universais da alma humana, ainda não estragada pelas convenções sociais e por preconceitos acadêmicos. Portanto, os visitantes que conhecem a arte infantil de seu país não encontrarão nestes desenhos de crianças inglesas qualquer nota de originalidade. Não é da natureza da criança ser original. O que faz é expressar diretamente sua individualidade, individualidade de uma criatura que vê e sente, não de alguém que pensa e inventa. (READ, 1941-1942a, p. 5).

O autor aproveitou a ocasião para criticar os "velhos métodos de ensino”, que ignoravam essas necessidades do público infantil, desconhecendo os estudos de psicologia mais recentes e exigindo o uso de habilidades de observação e análise estranhas ao estágio de seu desenvolvimento mental. Contrapunha sua crítica aos novos métodos os quais, embora não excluíssem necessariamente a observação e o espírito analítico, expresso nas naturezasmortas e paisagens presentes na mostra, antes tinham por objetivo o prazer da criança, permitindo-lhe plenamente que explorasse ao seu modo as ricas combinações de cores e tons. Isso só seria possível, segundo ele, deixando-se que a atividade se tornasse instintiva: "cumpre deixar que a criança descubra seu próprio potencial artístico" (READ, 1941-1942a, p. 5).

O envolvimento de Read com esse projeto resultou em um 
redirecionamento no sentido da aproximação com o campo educacional, que se traduziu num primeiro momento na publicação da obra "Educação pela Arte" (Education through Art), em 1943, a qual se tornaria referência para inúmeros educadores em diversos países no que se refere à presença da arte na educação. O livro apresentava inclusive, em sua primeira edição, alguns dos desenhos que participaram da exposição aqui analisada como materialização das ideias defendidas, a exemplo do reproduzido na imagem 2, que constava do catálogo da mostra realizada no Rio de Janeiro (READ, 1943, p. 240). A principal tese por ele defendida é que a arte deveria ser a base da educação, sendo seu objetivo principal estimular o desenvolvimento daquilo que é individual em cada ser humano, ao mesmo tempo harmonizando esta individualidade com a unidade orgânica do grupo social ao qual ele pertence (READ, 1943, p. 8). Presidente da Sociedade para a Educação em Arte desde 1946 até sua morte, Read teve papel fundamental no estabelecimento da Sociedade Internacional para Educação pela Arte (INSEA), em 1954, braço executivo da Unesco, com a qual colaborou ativamente em seus primeiros anos de funcionamento, tendo se dedicado a partir de então a reflexões teóricas sobre o tema ${ }^{14}$.

No contexto brasileiro, a mostra organizada por Read teve, como uma de suas preocupações, a mediação com o público visitante e com a comunidade em geral. Como parte do projeto e com o intuito de esclarecer os visitantes sobre os propósitos da exposição, a Associação de Artistas Brasileiros, sob a coordenação e seu presidente, o artista e professor Peregrino Junior, organizou uma série de debates públicos sobre desenho infantil, realizados no próprio local da mostra (O JORNAL, 14 out. 1941, p. 6). Entre os palestrantes se inclúáam: o professor Lourenço Filho, diretor do Instituto Nacional de Estudos Pedagógicos (INEP); Georgina de Albuquerque, professora da Escola de Belas Artes; Celso Kelly, jornalista, professor e crítico de arte; e Heloísa Marinho, professora do Instituto de Educação. Amplamente divulgadas na imprensa e

\footnotetext{
${ }^{14}$ Entre os textos publicados por Read sobre o tema da educação e de suas relações com a arte, podemos citar: The Education of Free Men (READ, 1944); Culture and Education in a World Order (READ, 1948); Education for Peace (READ, 1949); e The Redemption of the Robot: my encounter with Education Through Art (READ,1966).
} 
atraindo o interesse de educadores, artistas e interessados no tema da arte infantil, as palestras realizadas forneceram subsídios para reflexões tanto do ponto de vista das teorias pedagógicas sobre as relações entre o desenho e a psicologia infantil, como no que se refere à importância da autonomia da criança no processo de criação em arte, ampliando a arena de discussões sobre o assunto que em seguida tiveram lugar nos diversos veículos de comunicação.

Uma visada ao catálogo publicado por ocasião da mostra nos dá uma ideia do conteúdo a que o público teve acesso na ocasião. Apresentando em sua capa (Imagem 1) um desenho de autoria de um dos participantes, o documento trazia, além do texto de Read, um prefácio assinado por Sir Malcom Robertson, membro da comissão organizadora, bem como os nomes dos participantes categorizados por idades, sistemática que também foi seguida na organização dos trabalhos no espaço expositivo.

Figura 1: Capa do catálogo da Exposição organizada pelo British Council para o Brasil (19411942)

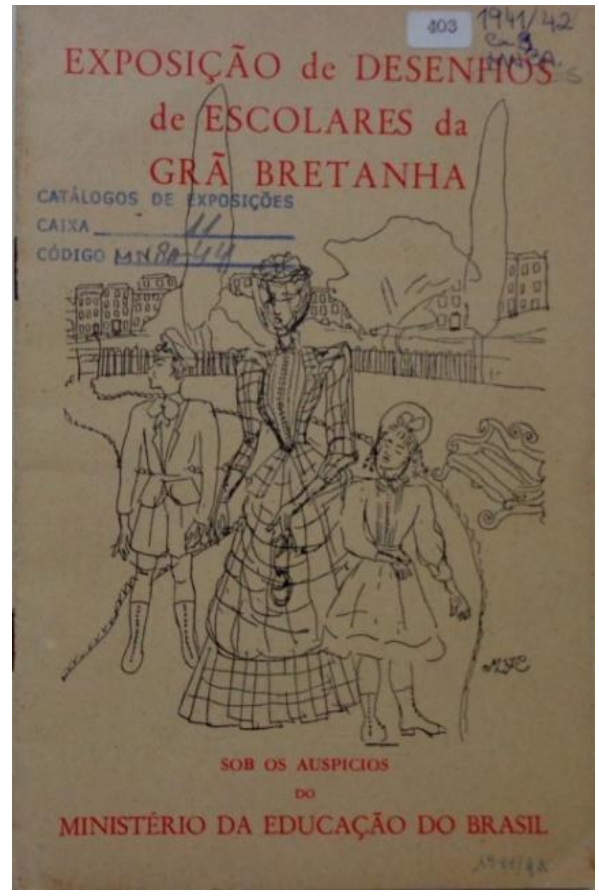


Fonte: (BRITISH COUNCIL, 1941-1942a).

Com relação às faixas etárias a distribuição foi desigual, tendo os adolescentes entre 12 e 17 anos representado quase dois terços do total de participantes. As crianças menores, entre 3 e 6 anos, cuja liberdade de expressão era tão louvada nos discursos modernos sobre o desenho infantil, perfizeram pouco mais de dez por cento do total, sendo que cerca de um quarto dos meninos e meninas participantes estava na faixa entre 7 e 11 anos. Um total 8 trabalhos foram reproduzidos em monocromia, o que de certa forma limita a análise da produção dos participantes, pois um dos elementos mais destacados nos depoimentos dos visitantes foi a riqueza cromática. Essas imagens abordam, em geral, temas ligados ao cotidiano infantil, tais como figuras humanas de corpo inteiro, animais de estimação, personagens como a florista, a mãe passeando com o bebê, figuras em trajes folclóricos (Imagem 2) ou grupos familiares. Também foram escolhidas cenas de zoológico com animais como tigres e leões marinhos, caçadas e cavalos selvagens. $\mathrm{O}$ universo da arte não se encontrava ausente na seleção que privilegiou, igualmente, gêneros pictóricos tradicionais como o retrato, a natureza morta (Imagem o3) ou a paisagem (BRITISH COUNCIL, 1941-1942a). 
Figura 2: Pintura de Margareth Astley, 13 anos, impressa no catálogo da Exposição de Escolares Britânicos

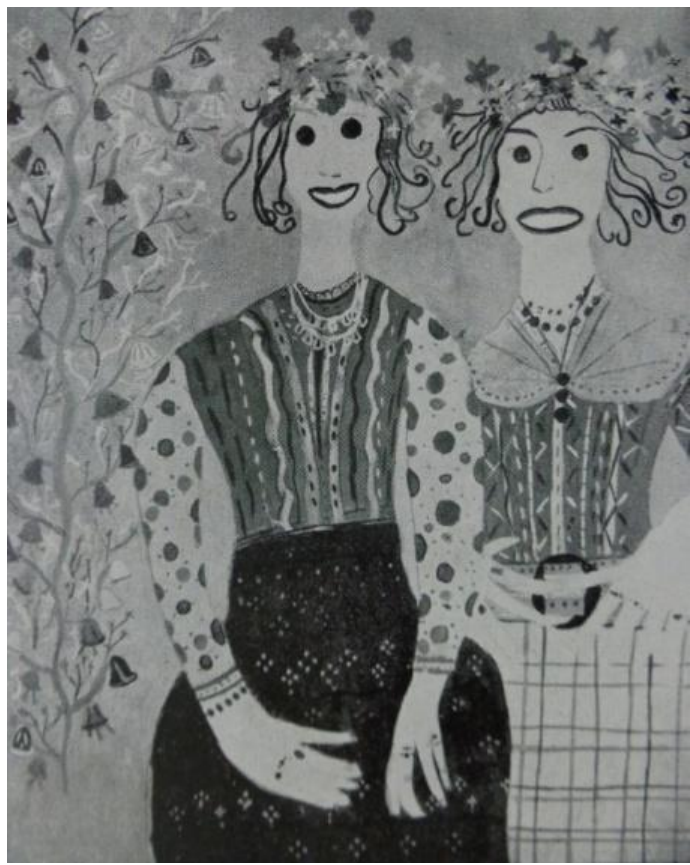

Fonte: (BRITISH COUNCIL, 1941-1942a, p. 16).

Figura 3: "Dálias num jarro", desenho de autor anônimo impresso no catálogo da Exposição de Escolares Britânicos que circulou Brasil

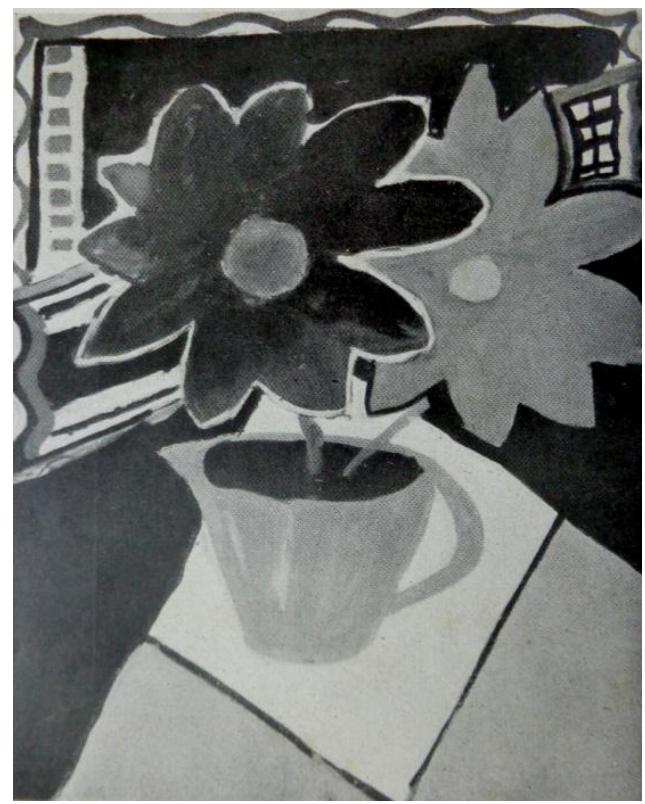

Fonte: (BRITISH COUNCIL, 1941-1942a, p. 18) 
Para Herbert Read, não seria atribuição do professor a imposição de temáticas a serem exploradas por seus alunos, cabendo-lhe uma ação meramente sugestiva. Seria necessário, porém, incentivar no ambiente escolar uma atmosfera que induzisse "a criança a exteriorizar a fantasia rica e cheia de vida que está na sua mente” (READ, 1941-1942a, p. 6). Ele também deveria evitar "não só as idiossincrasias do professor como artista, mas também os refinamentos e maneirismos de revistas, livros e filmes cinematográficos" (READ, 1941-1942a, p. 6), numa tentativa de preservar sua pureza expressiva. Sua tarefa seria "levar a criança ao reconhecimento, baseado em percepção e sensibilidade, do que é natural e espontâneo" (READ, 1941-1942a, p. 6).

Mesmo argumentando que temas escolhidos pelas crianças geralmente tendem "não para fantasias individuais, mas para incidentes dramáticos, tocados de um grande apelo coletivo" (READ, 1941-1942, p. 7), Read tendeu a minimizar a importância do impacto provocado pela situação de guerra em sua produção, justificando que os poucos trabalhos abordando a temática provinham de áreas distantes das áreas de conflito, sendo seu realismo "mais imaginativo que documentário". Ao afirmar não ser provável que a preocupação com o conflito, observada nos trabalhos de alunos de algumas escolas, fosse "devida ao choque da guerra, pois as crianças nunca fazem reportagens", afirmou que sua causa deveria ser procurada mais no contato com a imprensa ou o cinema, tratando-se de uma forma "de refinamento que o professor não pôde excluir da mentalidade de seus alunos” (READ, 1941-1942a. p. 7).

Embora os desenhos e pinturas com motivos bélicos não tenham sido escolhidos para ilustrar o catálogo da mostra, tampouco valorizados no discurso da organização, por alguns de seus títulos podemos ter alguma ideia dos temas que abordavam. Entre eles, podemos citar "Ataque aéreo", "Fábrica de aviões", "Escombros”, “Abrigo”, “Sentinela”, "Desastre de avião”, "Incêndio”, "Entrando na luta”, "Soldado alegre de folga" e "Guerra no mar" (BRITISH COUNCIL, 1941-1942a, p. 11-20). Tratados como exceção pela organização, tais trabalhos denotam, entretanto, que o olhar infantil não ignorava o contexto em que se 
encontrava imerso, sendo plausível que a pouca representatividade de tais assuntos se desse mais por uma eventual censura imposta pelo mecanismo do processo de seleção do que pela escolha deliberada de seus autores. Mesmo assim, alguns desses trabalhos devem ter causado forte impressão nos espectadores, expressa pelo testemunho escrito de alguns deles, como veremos adiante.

\section{NOTAS NA IMPRENSA: O OLHAR DE EDUCADORES, ARTISTAS E ESCRITORES}

Somando-se às explicações e informações das palestras sobre o assunto, as palavras de Read, impressas no catálogo da mostra, também contribuíram na condução do olhar de muitos dos visitantes. Essas impressões ficaram registradas nos textos publicados por artistas, jornalistas e escritores, os quais tinham em comum as manifestações de entusiasmo com relação ao que viram. Expressando, na maioria das vezes, uma visão pastoral ${ }^{15}$ desse fenômeno moderno, Manuel Bandeira, Vinícius de Moraes, Múcio Leão, Lourenço Filho, Rubem Navarra e Lasar Segall, entre outros, vieram a público em jornais diários e revistas para falar da pureza da expressão infantil, de suas qualidades estéticas, de suas características à luz da psicologia e de sua importância do ponto de vista educacional. Misturando o incentivo ao talento infantil à admiração pelos avanços pedagógicos da Grã-Bretanha, um texto publicado no jornal A Manhã afirmava:

Temperamentos os mais variados, inclinações as mais surpreendentes, vocações as mais positivas, estão representados nos quadros das crianças britânicas. A libertação dos seus sentimentos, das suas sugestões e da sua imaginação não sofre nenhum empecilho nem se

\footnotetext{
15 Marshall Berman (2007), na obra Tudo o que é sólido desmancha no ar: a aventura da modernidade utiliza os conceitos "pastoral" e "antipastoral" para classificar as diversas visões dos intelectuais, artistas e escritores sobre a modernidade vivenciada, o primeiro se referindo a uma abordagem de maravilhamento e aprovação, o segundo fazendo alusão ao desencantamento e à crítica do fenômeno moderno.
} 
encolhe diante de qualquer obstáculo, pois o método aplicado, aprendido nas lições da mais moderna pedagogia, dá às crianças toda a liberdade de ação no traço e no colorido. (A MANHÃ, 16 set. 1941, p. 8).

Para o jornalista e escritor Múcio Leão (14 out. 1941, p. 4), a mostra era "a maior prova de vitalidade que a Inglaterra poderia dar aos seus amigos da América do Sul", constituindo-se numa "manifestação de um universo novo", impossível de ser descoberto pelos adultos, no qual "a almazinha infantil se revela nuamente", sendo as obras apresentadas um verdadeiro milagre, dignas de admiração e "talvez de serem conservadas em museus". O incentivo dos professores à busca pelos meninos de um caminho próprio foi também por ele ressaltado: “Que eles próprios descubram, por si mesmos, o mundo, com os seus encantos e os seus sofrimentos; que encontrem também a melhor maneira de representar esse mundo". Leão acreditava ser a influência da guerra sobre as crianças "muito indireta”. Referendando o que já afirmara Read, considerava que em geral os desenhos a ela alusivos chegavam "de escolas muito distantes de qualquer ressonância do conflito" (LEÃO, 14 out. 1941, p. 4), prevalecendo na mostra temas mais leves, como o circo e a flor, entre outros por ele mencionados:

Do circo há vários quadros; de flores há uma dezena deles. Achei também a insistência dos bichos: meninos que fazem ursos polares, outros que representam lutas de elefantes com tigres, outros que reproduzem gatos. Um desenhista que ainda se lembra dos dias em que andava no berço, mostra uma criancinha conduzida no berço; um bebê que ficou com a recordação amarga de um banho que o obrigaram a tomar, agora reproduz caricaturalmente a mamãe ou a maninha mais velha, que o condenou a tal suplício, e a apresenta numa roupa amarela, bem vingativa [...]. (LEÃO, 14 out. 1941, p. 4)

A exposição também impressionou o poeta Manuel Bandeira (14 out. 1941, p. 8), que a considerou uma autêntica maravilha: "Nunca, em toda a minha vida, percebi uma exposição de artes plásticas mais deliciosa, mais 
completa e mais alta revelação de poesia”. Seu entusiasmo o levou a declarar publicamente que voltaria à mostra acompanhado de seu amigo Vinícius de Moraes, que por sua vez se sentiu motivado a comentar a mostra em sua coluna:

Vão à Exposição de Crianças Inglesas, em ver, ali pertinho, na Escola de Belas Artes. Ali tem mais moral, boa intenção, humanidade, singeleza, bravura, fraternidade, gênio, travessura, mau menino, bom menino, menino medíocre, menino inteligente, tudo quanto é de menino e de menina, cor, movimento, expressão, impressão, processo [...] (MORAES, 24 out. 1941, p. 5)

A liberdade expressa nos trabalhos das crianças também foi objeto de atenção de artigo assinado por "P. de S." ${ }^{16}$ para quem a fruição da exposição não dependia de se entender de pintura ou de arte, bastando apenas "saber ver e saber sentir”. $\mathrm{O}$ autor também fez alusão negativa à rigidez dos métodos das escolas de então:

Aqui o que há são desenhos de crianças. Desenhos livres como as almas infantis. Livres e anteriores a todos os preconceitos, inclusive o preconceito de escola, que é o pior de todos porque a beleza é uma coisa que existe em si mesma, que a gente descobre e revela, e nesse descobrimento e nessa revelação é que está a arte verdadeira e o verdadeiro artista. As escolas vêm depois, pra classificar, dividir, distribuir. E acontece que em arte o que importa é criar. O resto deve vir depois mesmo. (P. de S.,15 out. 1941, p. 4).

No entanto, as questões relacionadas ao conflito mundial, motivador da proposta, embora em geral abordadas de maneira mais tímida pelas editorias dos jornais ou pelos articulistas, também foram registradas por alguns deles. Ao lado da apreciação dos trabalhos propriamente ditos, o crítico Rubens Navarra deixava claro que a simpatia pela mostra também derivava da condição de oriunda de um país em guerra:

\footnotetext{
${ }^{16}$ Possivelmente Francisco Pereira da Silva, que atuou como redator do Diário Carioca no período mencionado (ASSOCIAÇÃO..., 2015).
} 
As crianças inglesas podiam não estar passando pelas desgraças da guerra, continuar vivendo à sombra das suas tranqüilas tradições, com isso não seria menos emocionante o interesse da galeria de arte infantil que anda percorrendo as Américas e chegou até nós. Neste momento é difícil resistir ao lado enternecedor dessa presença ideal, mas não precisamos de nenhum sentimento para simpatizar com tão significativa manifestação das forças constantes que fazem sobreviver a alma britânica: serenidade e liberdade. (NAVARRA, o9 nov. 1941, p. 1).

$\mathrm{Na}$ opinião do autor, as pinturas infantis valiam por centenas de discursos. Falavam de uma terra livre e de uma infância pura, consistindo na "documentação viva de uma cultura da liberdade", contraposta ao que ele imaginava que ocorreria no contexto de um regime autoritário:

Pensemos o que seriam os desenhos e as pinturas das crianças alemãs domesticadas pelo nazismo. Automatismo em vez de espontaneidade, uma imaginação livre deformada em instrumento de catequese, os cérebros dos meninos alemães metidos no sapato chinês do nazismo. Esta seria uma arte infantil, não livremente criada, mas fabricada de encomenda. (NAVARRA, o9 nov. 1941, p. 1).

Tomando claramente partido da Grã-Bretanha enquanto país aliado, Navarra procurava naturalizar os objetivos propagandísticos do certame:

É natural que haja uma intenção consciente da parte dos ingleses quando incumbem às suas crianças, em plena guerra, dessa mensagem que é um apelo moral à solidariedade americana: pois é um nobre intencionalismo o dessa propaganda que se vale do que há de mais humanamente puro e digno para justificar-se aos olhos do mundo. (NAVARRA, o9 nov. 1941, p. 1)

No entanto, mesmo sendo por ele mencionada, a guerra aparece na narrativa de Navarra como um mal inevitável, mas pouco percebido pelas crianças e com influência insignificante sobre suas vidas. A observação que dentre os trabalhos não se encontrava "nem a mais remota influência política se 
insinuando na imaginação da criança, nem mesmo a preocupação da guerra com suas cenas diárias", buscava menosprezar as conseqüências do conflito e valorizar a resiliência do povo britânico, tendo em vista que, para ele, o interesse da mostra estaria mais em sua lição educativa e artística do que "no alcance de sua nobre propaganda" ou no seu "significado moral" (Navarra, o9 nov. 1941, p. 1).

A efetividade da propaganda de guerra também se fazia notar nas palavras de A.M., correspondente do Diário de Pernambuco no Rio de Janeiro. Evidenciando o fato de os trabalhos terem chegado ao Brasil por via marítima, atravessando "zonas perigosas" e enfrentando os "corsários alemães" o autor afirmava ser essa uma demonstração de que a Inglaterra ainda era "a rainha dos mares e senhora de todos os oceanos", tendo transportado "tranquilamente, fleumaticamente, sem receio algum as várias centenas de desenhos feitos pelos guris ingleses nas horas em que as sirenes de alerta não perturbam sua calma, para mostrá-los aos seus coleguinhas brasileiros" (A.M., 17 out. 1941, p. 2).

As poucas imagens produzidas sobre o tema da guerra presentes na mostra, realizadas pelas crianças maiores, foram relacionadas ao conflito mundial de forma parcial e relativizada pelos comentaristas, podendo significar, na opinião de P. de S. (15 out. 1941, p. 4), "o heroísmo da sobrevivência do espírito no meio da morte e da estupidez", numa alusão à pretensa superioridade do povo britânico, que mesmo em tempo de guerra seria capaz de manter funcionando atividades relacionadas à educação e às artes. Não obstante, esse conjunto de trabalhos mereceu a atenção do articulista que assina como C. (12 out. 1941, p. 9):

Mas o grupo dos treze anos tem uma inspiração menos sossegada. Algumas paisagens e cenas de rua não são suficientes para contrabalançar a fábrica de aviões, os escombros, o abrigo anti-aéreo, o desastre de aviação, - sombrios motivos que reaparecerão mais para diante, com cenas de bombardeio, de incêndio, de guerra no mar e na terra, e um "tédio" desenhado por uma criança de quinze anos - como se em tal idade já se estivesse não entrando, mas saindo da vida, com o cansaço do tempo, pelo desequilíbrio do mundo. (C., 12 out. 1941, p. 
9).

Criticando aqueles que não viam qualidades na mostra por compará-la com a produção artística de profissionais, C. argumentava que, naquele momento, exposições como aquela deveriam ser motivos de reflexão por significarem "uma primavera sobre a morte, um nascimento em pleno desastre" (C., 12 out. 1941, p. 9).

Também foi essa produção, que abordava o conflito bélico de forma mais direta, que chamou a atenção de Leonardo Silva por ocasião de sua visita à mostra. Em meio aos trabalhos que em sua opinião tendiam para o decorativo, para o retrato, para a paisagem e para um certo "humanismo doloroso", destacou duas pinturas que abordavam temáticas vinculadas à guerra. A primeira apresentava um abrigo anti-aéreo, que na opinião do autor expressava “o drama daquelas vidas que se procuram salvar do inimigo cruel”, sendo possível sentir, "na promiscuidade reinante", a angústia daqueles "dias tumultuosos, o sofrimento que se percebe e se comove”. O trabalho teria sido executado por um "pobre pequenino artista", capaz de ver apenas "a dor, a miséria, o terror" (SILVA, 01 nov. 1941, p. 17). A segunda pintura por ele comentada trazia como tema um bombardeio da capital britânica, explicitando na própria forma seus aspectos trágicos: “A própria tonalidade do desenho é uma expressão de dor, é uma tarja de luto emoldurando a sensibilidade infantil do seu autor”. (SILVA, 1941, p. 17).

Depois de encantar o Rio de Janeiro, a Exposição de Desenhos de Escolares Britânicos também viajou para São Paulo, sendo exibida na Galeria Prestes Maia (O ESTADO DE SÃO PAULO, 10 dez. 1941, p. 11). Realizada pelo Departamento Municipal de Cultura e patrocinada por instituições como o Departamento de Educação, Conselho de Orientação Artística, Sindicado dos Artistas Plásticos, Família Artística Paulista, Associação Paulista de Imprensa e Salão de Maio, mereceu pronunciamento em forma de palestra do artista Flávio de Carvalho (CORREIO PAULISTANO, 02 dez. 1941, p. 3). Também itinerou no 
ano seguinte por Belo Horizonte (A MANHÃ, 16 jan. 1942, p. 8), ocasião em que contou com o apoio de intelectuais como Helena Antipoff, Mário Matos e Charles Hindley, passando posteriormente por Curitiba (ALBIZÚ, 16 ago. 1942, p. 4).

A ideia serviu de estímulo a outros projetos, a exemplo da exposição de desenhos de crianças brasileiras, organizada pela Radio Tupi e pelo Diário da Noite, do Rio de Janeiro, exposta na Escola Nacional de Belas Artes, e que seguiu posteriormente para ser exibida em Londres. (DIÁRIO DA NOITE, 19 out. 1942, p. 3). Em 1944, a exposição intitulada "A guerra vista pelas crianças de várias partes do mundo", ocorrida em Londres, abordaria o tema em exposição congênere (DIÁRIO DA NOITE, 17 mar. 1944, p. 1-2).

Findo o conflito, a mostra dos pequenos ingleses seria rememorada por diversas vezes como um marco incentivador das ações voltadas à arte e à educação. O lema da livre-expressão, proposto na ocasião por Herbert Read, foi a bússola norteadora de projetos realizados nos moldes das escolinhas de arte por várias décadas. Nesses projetos, as exposições de arte infantil se tornaram ações imprescindíveis, dando visibilidade à expressão artística das crianças ao redor do mundo e possibilitando intercâmbios entre as diversas regiões do país.

\section{CONSIDERAÇÕES FINAIS}

Organizada pelo Conselho Britânico, órgão criado para divulgar uma boa imagem da Grã-Bretanha no exterior, a Exposição de Desenhos de Escolares Britânicos consistiu em parte dos esforços propagandísticos para conquistar a simpatia de países como o Brasil para as forças aliadas no contexto da Segunda Guerra Mundial, valorizando sua cultura e estilo de vida. Encontrando um terreno favorável em que a criança tinha grande espaço e atenção da mídia, de instituições e das autoridades, a exposição teve lugar num espaço de grande valor simbólico, o Museu Nacional de Belas Artes, o qual 
abriga tradicionalmente obras de artistas de reconhecimento nacional e internacional. Este fator, aliado ao próprio clima de polarização fomentado pela situação de guerra, resultou em grande sucesso de público e crítica. A natureza do projeto, realizado a partir de ideias modernas vinculadas à arte e à educação, de valorização da liberdade de expressão e da individualidade da criança, sensibilizou a imprensa e a intelectualidade brasileiras, que se manifestaram pública e entusiasticamente sobre os trabalhos apresentados e sobre os aspectos conceituais da mostra, merecendo tratamento diferenciado em relação a evento similar que ocorrera pouco tempo antes, apresentando trabalhos artísticos de crianças francesas.

No entanto, nas impressões registradas sobre a produção artística das crianças, prevaleceram as de ordem estética e educacional, em detrimento daquelas que analisavam suas implicações políticas. As relações das crianças com a guerra, personificadas em algumas pinturas mostradas no certame e em sua própria natureza organizacional, foram minimizadas pelos porta-vozes da mostra e pela maior parte dos visitantes que a comentaram, os quais não parecem ter levado em consideração que o que estava sendo mostrado era fruto de uma seleção feita por adultos, encerrando uma intenção em que as representações da guerra poderiam ter sido propositalmente preteridas.

Envolvendo especialistas da arte e da educação, a mostra foi organizada contemplando tanto aspectos relacionados à psicologia do desenho infantil, expressos na divisão das seções em faixas etárias e nos conteúdos das palestras proferidas, como questões estéticas, presentes nas temáticas selecionadas ou no tratamento livre dado aos trabalhos escolhidos. A iniciativa motivou debates, palestras e reflexões publicadas em veículos da imprensa. Também foi propulsora de projetos que viriam a florescer futuramente, como a Escolinha de Arte do Brasil e outras instituições congêneres.

Por onde passou, a mostra mereceu elogios e suscitou debates sobre o valor da arte infantil, cumprindo os objetivos de representação e promoção da Grã-Bretanha como um país adiantado educacional e culturalmente, respeitador 
da liberdade e destemido na guerra. Contribuiu possivelmente, também para que muitos brasileiros simpatizassem com aquele país, no jogo polarizado da Segunda Guerra Mundial em que gradativamente as tomadas de posição se tornavam necessárias.

\section{REFERÊNCIAS}

A MANHÃ. $1^{\circ}$ Salão de Arte Infantil. Rio de Janeiro, 10 out. 1941, p. 1.

A MANHÃ. Belo Horizonte. Rio de Janeiro, 16 jan. 1942, p. 8.

A MANHÃ. Concurso de robustez infantil. Rio de Janeiro, 10 ago. 1941, p. 1.

A MANHÃ. Exposição de desenho de crianças britânicas. Rio de Janeiro, 16 set. 1941, p. 8.

A.M. Exposição de crianças inglesas. Diário de Pernambuco, Recife, 17 out. 1941, p. 2.

ALBIZÚ, Francisco. Exposição de desenhos de escolares da Grã-Bretanha.

Gazeta do Povo, Curitiba, 16 ago. 1942, p. 4.

ASSOCIAÇÃO Brasileira de Imprensa. Diário Carioca: o jornal que fez história. Disponível em: http://www.abi.org.br/diario-carioca-o-jornal-que-fezhistoria/. Acesso em: 10 nov. 2015.

BANDEIRA, Manuel. A exposição de desenhos e pinturas das crianças é uma maravilha. A Manhã, Rio de Janeiro, 14 out. 1941, p. 8.

BARBOSA, Ana Mae. Arte Educação no Brasil: das origens ao modernismo. São Paulo: Perspectiva, 1978.

BARBOSA, Ana Mae. As exposições infantis: modernismo e culturalismo. In: Anais do $21^{\circ}$ Encontro Nacional da ANPAP, Rio de Janeiro: UERJ, 2012, p. 314-326. Disponível em: http://www.anpap.org.br/anais/2012/pdf/simposio3/ana mae barbosa.pdf. Acesso em: 30 set. 2013.

BARBOSA, Ana Mae. John Dewey e o ensino da arte no Brasil. São Paulo: Cortez, 2001. 
BARBOSA, Ana Mae. Redesenhando o desenho: educadores, política e história. São Paulo: Cortez, 2015.

BERMAN, Marshall. Tudo o que é sólido desmancha no ar: a aventura da modernidade. São Paulo: Companhia das Letras, 2001. Tradução: Carlos Felipe Moisés, Ana Maria L. Ioriatti.

BRITISH COUNCIL. Exposição de Desenhos de Escolares da Grã Bretanha. London: 1941-1942a.

BRITISH COUNCIL. History. Disponível em: http://www.britishcouncil.org/organisation/history. Acesso em: 10 mai. 2015. C. Desenhos de crianças inglesas. A Manhã, Rio de Janeiro, 12 out. 1941, p. 9. CAZALS, Rémy. Les écoliers de Tournissan (1939-1945). Toulouse: Privat, 1978.

CORREIO DA MANHÃ. Exposição de desenhos das crianças britânicas. Rio de Janeiro, 12 out. 1941, p. 2.

CORREIO DA MANHÃ. Exposição de gravuras britânicas contemporâneas. Sua próxima inauguração no Museu de Belas Artes. Rio de Janeiro, 16 mai. 1942, p. 3.

CORREIO DA MANHÃ. Inaugurada a Exposição de desenhos de crianças francesas. Rio de Janeiro, 30 ago. 1941, p. 3.

CORREIO DA MANHÃ. Tijuca Tennis Club. Rio de janeiro, 17 jul. 1940, p. 9. CORREIO PAULISTANO. Inaugurada a exposição de desenhos de escolares da Grã-Bretanha. São Paulo, 02 dez. 1941, p. 3.

DIÁRIO CARIOCA. Cooperação Cultural Anglo-Americana - a alocução de Sir. Robertson. Rio de Janeiro, 11 jul. 1941, p. 2.

DIÁRIO DA NOITE. As maiores vítimas de Hitler. Rio de Janeiro, 17 mar. 1944, p. 1-2.

DIÁRIO DA NOITE. Desenhos das crianças brasileiras para as crianças de Londres. Rio de Janeiro,19 out. 1942, p. 3.

DIÁRIO DA NOITE. Exposição de arte infantil em São Paulo. Rio de Janeiro, 01 ago. 1941, p. 5.

DIÁRIO DE NOTÍCIAS. Desenhos de crianças francesas. Rio de Janeiro, 28 ago. 1941, p. 11. 
DIÁRIO DE NOTÍCIAS. Exposição de desenhos de escolares da GrãBretanha. Rio de Janeiro, 11 out. 1941, p. 5.

ENCLICLOPAEDIA BRITANNICA. Sir Herbert Read. Disponível em: https://www.britannica.com/biography/Herbert-Read-British-art-critic. Acesso em: 09 jun. 2019.

GAZETA DE NOTÍCIAS. Exposição de desenhos de crianças francesas. Rio de Janeiro, 30 ago. 1941, p. 13.

GAZETA DE NOTÍCIAS. O problema da alimentação na Europa. Auxílio às crianças francesas. Rio de Janeiro, 24 ago. 1941, p. 22.

GOBBI, Márcia Aparecida. Mário de Andrade e os desenhos das crianças pequenas: olhares de "turista aprendiz". In: FREITAS, Marcos Cezar de. Desigualdade social e diversidade cultural na infância e na juventude. São Paulo: Cortez, 2006.

GRIBAUDI, Maurizio. Escala, pertinência, configuração. In: REVEL, Jacques (org.). Jogos de escalas: A experiência da microanálise. Tradução Dora Rocha. Rio de Janeiro: Editora Fundação Getúlio Vargas, 1998.

INEP (Instituto Nacional de Estudos e Pesquisas Educacionais). Escolinha de Arte do Brasil. Brasília, 1980.

KELLY, Donna Darling. Uncovering the History of Children's Drawing and Art. Westport, Connecticut, London: Praeger, 2004.

LEÃO, Múcio. Desenhos de Crianças. A Manhã, Rio de Janeiro, 14 out. 1941, p. 4.

LEPETIT, Bernard. Sobre a escala na história. In: REVEL, Jacques (org.). Jogos de escalas: A experiência da microanálise. Tradução Dora Rocha. Rio de Janeiro: Editora Fundação Getúlio Vargas, 1998.

LYNTON, Norbert. Expressionismo. In: STANGOS, Nikos (org.). Conceitos da Arte Moderna. Tradução Álvaro Cabral. Rio de Janeiro: Jorge Zahar, 1991.

MARIA ISABEL. A criança e seus problemas. A Manhã, Rio de Janeiro, 16 set. 1941, p. 8.

MEIRELES, Cecília. Crônicas de educação, 4. Rio de Janeiro: Nova Fronteira, Biblioteca Nacional, 2001.

MORAES, Vinícius de. Cinema. A Manhã, Rio de Janeiro, 24 out. 1941, p. 5. 
NAVARRA, Rubem. Sobre a exposição de meninos ingleses. O Jornal, Rio de Janeiro, 9 nov. 1941, p. 1.

O ESTADO DE SÃO PAULO. Exposição de desenhos de crianças inglesas. São Paulo, 10 dez. 1941, p. 11.

O JORNAL. A exposição de desenhos de crianças inglesas. Rio de Janeiro, 14 out. 1941, p. 6.

O JORNAL. Inaugura-se hoje a exposição de desenhos de crianças inglesas. Rio de Janeiro, 11 out. 1941, p. 10.

O JORNAL. Uma festa de 3000 crianças, promovida pelo Rotary Club. Rio de Janeiro, 31 dez. 1941, p. 7.

OSINSKI, Dulce Regina Baggio "Uma renovação no conceito das exposições escolares': a $1^{\text {a }}$ Exposição de Arte Infantil e Juvenil do Paraná (1943). Revista Brasileira de Educação (Impresso), v.19, p.375 - 398, 2014.

OSINSKI, Dulce Regina Baggio. Guido Viaro: Modernidade na arte e na educação. Tese (Doutorado) - Setor de Educação, Universidade Federal do Paraná, Curitiba, 2006.

OSINSKI, Dulce Regina Baggio; ANTONIO, Ricardo Carneiro. Criança livre ou artista mirim? As exposições de arte infantil no Paraná (1940-1960). Impulso, Piracicaba, v. 20, p. 49-61, 2010a.

OSINSKI, Dulce Regina Baggio; ANTONIO, Ricardo Carneiro. Exposições de arte infantil: bandeiras modernas pela construção do novo homem. Acta Scientiarum, Maringá, Education (Print), v. 32, p. 269-285, $2010 b$.

OSINSKI, Dulce Regina Baggio; SILVA, João Paulo de Souza da. $1^{\mathrm{a}}$ Exposição de Pintura do Centro Juvenil de Artes Plásticas: a presença da criança nas comemorações do Centenário do Paraná (1953). In: VIEIRA, Carlos Eduardo; STRANG, Bernadete de Lourdes Streisky; OSINSKI, Dulce Regina Baggio; (orgs.). História Intelectual e Educação: Trajetórias, Impressos e Eventos. Jundiaí, SP: Paco Editorial, 2015, p. 381-404.

OSINSKI, Dulce Regina Baggio; SIMAO, Giovana Terezinha. Emma Kleè Koch e as exposições de arte infantil: rituais coloridos pela educação moderna (19491952). Revista Brasileira de História da Educação, v.14, p.195 - 222, 2014 .

P. de S. Os Desenhos das Crianças Inglesas. Diário Carioca, Rio de Janeiro, 15 out. 1941, p. 4 . A cidade. 
RA.FORUM. Read, Herbert - Bibliography. Disponível em:

http://raforum.site/spip.php?article7401. Acesso em: 10 jun. 2019.

READ, Herbert. Education for Peace. New York: Scribner, 1949.

READ, Herbert. Education through Art. London: Faber and Faber, 1943.

READ, Herbert. Introdução. In: BRITISH COUNCIL. Exposição de Desenhos de Escolares da Grã Bretanha. London: 1941-1942a.

READ. Herbert. Introduction. In: BRITISH COUNCIL. The British Council Exhibition os British Children's Drawings. Canadá and The United States of America - 1941-1942. London; Northampton: Clarke \& Sherwell, 1941.

READ, Herbert. The Education of Free Men. London: Freedom Press, 1944.

READ, Herbert. Culture and Education in a World Order. New York: Museum of Modern Art, 1948.

READ, Herbert. The Redemption of the Robot: my encounter with Education Through Arte. New York : Trident Press, 1966.

REVEL, Jacques. Microanálise e construção do social. In: REVEL, Jacques (org.). Jogos de escalas: A experiência da microanálise. Tradução Dora Rocha. Rio de Janeiro: Editora Fundação Getúlio Vargas, 1998.

ROOSEVELT, Eleanor. Meu dia. Diário de Notícias, 07 mar. 1941, p. 5.

SELZ, Peter. Fauvismo e expressionismo: a intuição criadora (introdução). In: CHIPP, Herschel Browning. Teorias da Arte Moderna. Tradução Waltensir Dutra et al. São Paulo: Martins Fontes, 1996.

SILVA, Leonardo. Da arte emocional de Presciliano Silva aos desenhos das crianças inglesas. Revista da Semana. Rio de Janeiro, ano XVII, $n^{\circ} 44,01$ nov. 1941, p. 17.

SILVEIRA, Joel. Margareth e John pintam para os homens. Diretrizes, Rio de Janeiro, ano IV, $\mathrm{n}^{0}$ 49, 16 out. 1941.

THISTLEWOOD, David. "Imagination need not die": Alexander BarclayRussell's work on Education in Art. JournalofArt\& Design Education, vol. $2, \mathrm{n}^{0} 2,1983$. p. $171-183$.

THISTLEWOOD, David. Herbert Read (1893-1968).Prospects: the quartely revew of comparative educacion, Paris, UNESCO: International Bureau of Education, vol. 24, n. 1/2, 1994, p. 375-390. Disponível em: http/www.ibe. 
unesco.org/ thinkerspdf/ read.pdf. Acesso em: 13 mai. 2015.

TOURAINE, Alain. Crítica da modernidade. Tradução Elia Ferreira Edel. Petrópolis, RJ: Vozes, 1994.

VIEIRA, Carlos Eduardo. Jornal diário como fonte e como tema para a pesquisa em História da Educação: um estudo da relação entre imprensa, intelectuais e modernidade nos anos de 1920. In: OLIVEIRA, Marcus Aurélio Taborda de (org.). Cinco estudos em história e historiografia da educação. Belo Horizonte: Autêntica, 2007.

VIOLA, Wilhelm. Child Art and Franz Cizek. Vienna: Austrian Junior Red Cross, 1936.

WILSON, Brent. Mudando conceitos da criação artística: 500 anos de arteeducação para crianças. In: Simpósio Internacional sobre o ensino da arte e dua história (1989, São Paulo). O ensino da arte e sua história. São Paulo: MAC/USP, 1990.

WHITFIELD, Sarah. Fauvismo. In: STANGOS, Nikos (org.). Conceitos da Arte Moderna. Tradução Álvaro Cabral. Rio de Janeiro: Jorge Zahar, 1991.

DULCE REGINA BAGGIO OSINSKI é professora do Programa de Pósgraduação em educação da Universidade Federal do Paraná, na linha de pesquisa História e Historiografia da Educação. Coordenadora do Grupo de Pesquisa História Intelectual e Educação (GPHIE) junto ao CNPq.

E-mail: dulceosinski@gmail.com

(1) http://orcid.org/0000-0002-3506-4974 